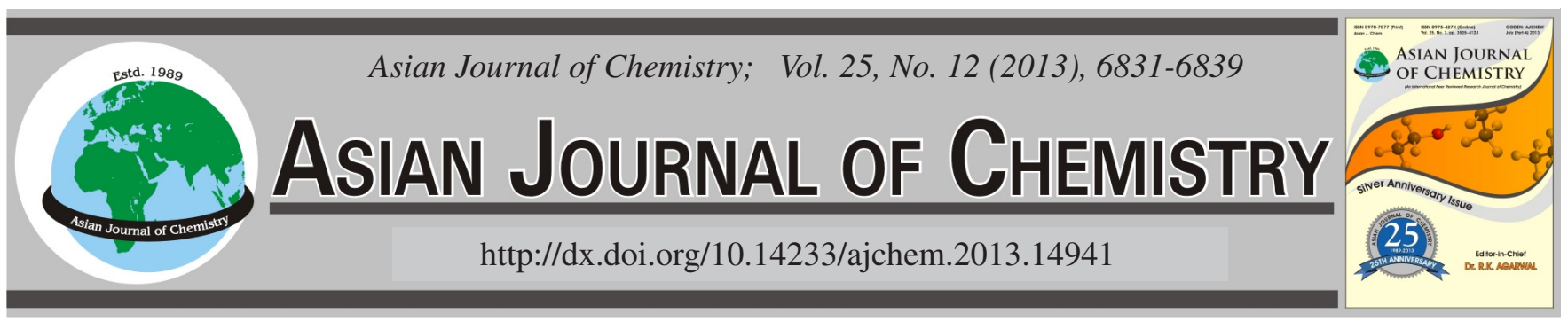

\title{
Response Surface Methodology for Oxidative Degradation of the Basic Yellow 28 Dye by Temperature and Ferrous Ion Activated Persulfate
}

\author{
Belgin Gözmen ${ }^{1, *}$, ÖZgür Sönmez ${ }^{1}$ and Meral TurabiK ${ }^{2}$
}

${ }^{1}$ Department of Chemistry, Faculty of Science \& Arts, Mersin University, Yenisehir, Mersin 33343, Turkey ${ }^{2}$ Chemical Prog., Technical Science Vocational School, Mersin University, Yenisehir, Mersin 33343, Turkey

*Corresponding author: Fax: +90 324 3610046; Tel: +90 324 3610001; E-mail: bgozmen@ @ersin.edu.tr

\begin{abstract}
The decomposition of the persulfate by $\mathrm{Fe}^{2+}$ ions results in the production of oxidative sulfate radical anions. In present study, the oxidative degradation of the basic yellow 28 dye solution was studied by using persulfate and ferrous ions. To obtain maximum mineralization efficiency for aqueous solution of basic yellow 28, Box-Behnken design combined with response surface modeling (RSM). Four independent variables, namely temperature $\left(40-70{ }^{\circ} \mathrm{C}\right)$, initial concentration of persulfate $(4-12 \mathrm{mM})$, ferrous ion $(1-3 \mathrm{mM})$ and time $(2-8 \mathrm{~h})$ were transformed to coded values. Subsequently, it was determined that quadratic model to be the most suitable models to estimate the responses. Analysis of variance (ANOVA) was carried out for quadratic model and was observed the significance of the independent variables and their interactions. The predicted values of the oxidative degradation efficiency were verified to be in good agreement with the experimental values $\left(R^{2}=0.9902\right.$ and $\left.R_{\text {adj }}^{2}=0.9804\right)$. Maximum mineralization efficiency $93 \%$ was obtained under following conditions: persulfate concentration $9.87 \mathrm{mM}$, ferrous ion concentration $1.95 \mathrm{mM}$, temperature at $65^{\circ} \mathrm{C}$ and time at $8 \mathrm{~h}$ for $40 \mathrm{mg} / \mathrm{L}$ basic yellow 28 aqueous solution.
\end{abstract}

Key Words: Oxidative degradation, Green chemistry, Basic yellow 28, Persulfate, Response surface methodology, Box-Behnken design.

\section{INTRODUCTION}

During the dye production and textile manufacturing processes, large volumes of dyeing wastewater which has the potential of toxicity and intense colour has been left into aquatic systems. Even if dye concentrations were low values (e.g., $10-20 \mathrm{mg} \mathrm{L}^{-1}$ ), it affects the water transparency and solubility of gases in water. Besides, the cationic dyes are generally considered to be more toxic in comparison to the anionic dyes toward the aquatic biota ${ }^{1}$. This is because cationic dyes easily interact with the membrane surfaces of the negatively charged cells, enters into the cells and concentrates in the cytoplasm ${ }^{2}$. Subsequently, the symbiotic process is affected as the natural equilibrium is disturbed by the reduced photosynthetic activity. The above mentioned reduction in the photosynthetic activity is due to the colouration of the water in the streams.

In recent years, there has been growing interest in the use of persulfate $\left(\mathrm{S}_{2} \mathrm{O}_{8}{ }^{2-}\right)$, which is one of the strongest oxidants known in aqueous solutions $\mathrm{s}^{3-5}$. It offers certain advantages over other oxidants, such as high stability at room temperature, high aqueous solubility, a solid fact that can be easily stored and transferred and relatively low cost $t^{6,7}$. Persulfate anion with a redox potential of $2.01 \mathrm{~V}$ is a non-selective oxidant. This oxidant can be decomposed by heat, UV light or transition metal ions $\left(\mathrm{Me}^{\mathrm{n}+}\right)$, such as $\mathrm{Fe}^{2+}$. Subsequently, this leads to the formation of $\mathrm{SO}_{4}{ }^{--}$, which exhibits a redox potential of $2.6 \mathrm{~V}^{8,9}$.

$$
\begin{gathered}
\mathrm{S}_{2} \mathrm{O}_{8}{ }^{2-}+\text { heat } / \mathrm{UV} \longrightarrow 2 \mathrm{SO}_{4}{ }^{--} \\
\mathrm{S}_{2} \mathrm{O}_{8}{ }^{2-}+\mathrm{Me}^{\mathrm{n}+} \longrightarrow \mathrm{SO}_{4}{ }^{--}+\mathrm{Me}^{(\mathrm{n}+1)+}+\mathrm{SO}_{4}{ }^{2-}
\end{gathered}
$$

If a ferrous ion is used as the transition metal:

$$
\mathrm{S}_{2} \mathrm{O}_{8}{ }^{2-}+\mathrm{Fe}^{2+} \rightarrow \mathrm{SO}_{4}{ }^{--}+\mathrm{Fe}^{3+}+\mathrm{SO}_{4}{ }^{2-} \quad\left(\mathrm{k}=27 \mathrm{M}^{-1} \mathrm{~s}^{-1}\right)
$$

In a persulfate-water system, hydroxyl radicals can also be formed, as shown in eqns. 4-5. The hydroxyl radicals may participate in the oxidation of the contaminants ${ }^{10}$.

$$
\begin{gathered}
\mathrm{SO}_{4}{ }^{\bullet-}+\mathrm{H}_{2} \mathrm{O} \longrightarrow \mathrm{OH}^{\bullet}+\mathrm{HSO}_{4}{ }^{-} \quad\left(\mathrm{k}=500 \mathrm{~s}^{-1}\right) \\
\mathrm{SO}_{4}{ }^{--}+\mathrm{OH}^{-} \longrightarrow \mathrm{SO}_{4}{ }^{2-}+\mathrm{OH}^{\bullet}
\end{gathered}
$$

Response surface methods (RSM) offer statistical design of experiment tools that lead to peak process performance. The RSM-based modeling studies have been widely used in many wastewater treatment systems such as photocatalytic oxidation $^{11}$, Fenton/photo-Fenton ${ }^{12,13}$, electro-Fenton/photoelectron-Fenton ${ }^{14,15}$, electrochemical oxidation ${ }^{16}$, ozonation ${ }^{17}$, wet air oxidation ${ }^{18}$ and adsorption ${ }^{19,20}$ for various pollutants. To our best of knowledge, optimization of oxidative degradation 
process parameters of persulfate/iron/temperature system to obtain maximum mineralization of basic yellow 28 by using with the Box-Behnken design has not been study conducted until now. Many researchers had investigated the alone oxidative effect of the heat, persulfate dosage and/or metal ions amount on activated persulfate by temperature or metal ions for various types of organics ${ }^{21-25}$. Anipsitakis and Dionysiou ${ }^{5}$ investigated the activation of persulfate by 9 different transition metals including $\mathrm{Ag}^{+}, \mathrm{Ce}^{3+}, \mathrm{Co}^{2+}, \mathrm{Fe}^{2+}, \mathrm{Fe}^{3+}, \mathrm{Mn}^{2+}, \mathrm{Ni}^{2+}, \mathrm{Ru}^{3+}$ and $\mathrm{V}^{3+}$ and reported that $\mathrm{Ag}^{+}$is the best activating agent for persulfate. Despite this result, in environmental applications iron is often used due to environmentally friendly nature, cost effectiveness. However, Liang et al. $^{4}$ found that $\mathrm{Fe}^{2+}$ used in small increment In previous studies have shown that an increase in $\mathrm{pH}^{3,5,7,25}$ and ionic strength ${ }^{3,25}$ resulted in a decrease in the rate constant of organic pollutants. $\mathrm{Xu}$ and $\mathrm{Li}^{7}$ reported that the inhibiting effects of some ions ranged from low to high in an order of $\mathrm{NO}_{3}{ }^{-}<\mathrm{Cl}^{-}<\mathrm{H}_{2} \mathrm{PO}_{4}^{-}<\mathrm{HCO}_{3}^{-}$. It has been known that in the neutral and alkaline media, the amounts of soluble $\mathrm{Fe}^{2+}$ and $\mathrm{Fe}^{3+}$ could decrease due to the formation of complexes and precipitations. For this reason, the chelating agents were employed to stabilize the iron in solution at near neutral $\mathrm{pH}$ or $\mathrm{pH}$ of the solution was adjusted under $\mathrm{pH} 4$ value. Some of previous studies have been performed to determine the optimum conditions, but in most of them one of the three variables (temperature, persulfate concentration, $\mathrm{Fe}^{2+}$ concentration) were kept constant ${ }^{7,24,26}$. Also optimum values obtained from these studies differ from each other.

In the present study, basic yellow 28 (Cationic Gold Yellow X-GL) which is a synthetic basic cationic dye, imparts a yellow colour in the aqueous solution, was selected as the target dye. A series of experiments were conducted at ambient temperatures (between $40-70^{\circ} \mathrm{C}$ ) to evaluate the effectiveness of the persulfate oxidation that activated by ferrous ion for the destruction of basic yellow 28. The Box-Behnken design of Design Expert ${ }^{\circledR} 8$ program was used for the response surface methodology in the experimental design during the first series of experiments. The experiments were designed to determine the influence of factors, such as temperature, initial ferrous ion and persulfate concentrations and time on the degradation as well as studying the optimum working state. The second series of experiments were investigated for the oxidative degradation pathway of basic yellow 28 at optimum conditions.

\section{EXPERIMENTAL}

Response surface modeling: Response surface methodology (RSM) uses mathematical and statistical techniques to fit of a polynominal equation to the experimental data, which should be the objective of making the statistical previsions ${ }^{27}$. Determine the optimum set of operational variables for a process is the main goal of the RSM. The statistical experimental designing with RSM can reduce the process variability, experimentation time as well as the overall cost with an improved process output $^{28}$. The Box-Behnken design (BBD) of Design Expert ${ }^{\circledR} 8$ program was used for the RSM in the experimental design where each factor takes only three levels. This design is more efficient and economical according to the other $3 \mathrm{k}$ designs, especially for a large number of variables ${ }^{28}$. The independent variables of temperature, processing time, initial $\mathrm{K}_{2} \mathrm{~S}_{2} \mathrm{O}_{8}$ and initial $\mathrm{FeSO}_{4}$ concentration were coded with the low and high levels in the Box-Behnken design, as shown in Table-1. The mineralization per cent (TOC removal\%) of the basic yellow 28 solution was the obtained response. In the optimization process, the responses can be simply related to the chosen factors by the linear or quadratic models. A quadratic model is shown as follows:

$$
Y=\beta_{0}+\sum_{j=1}^{k} \beta_{j} x_{j}+\sum_{j=1}^{k} \beta_{j j} x_{j}^{2}+\sum_{i} \sum_{<j=2}^{k} \beta_{i j} x_{i} x_{j}+e_{i}
$$

where, $\mathrm{Y}$ is the response, $\mathrm{k}$ is the number of factors, $\mathrm{X}_{\mathrm{i}}$ and $\mathrm{x}_{\mathrm{j}}$ are the coded variables, $\beta_{0}$ is the offset term, $\beta_{\mathrm{j}}, \beta_{\mathrm{jj}}$ and $\beta_{\mathrm{ij}}$ are the first-order, quadratic and interaction effects respectively, $i$ and $\mathrm{j}$ are the index numbers for factor and $\mathrm{e}_{\mathrm{i}}$ is the residual error $^{29}$.

Model fitting and graphical analyses were carried out using the Design-Expert software. Soundness of the fit was studied using F-test, p-value, chi-square $\left(\mathrm{X}^{2}\right)$, the root mean square error of prediction (RMSEP) and the relative error of prediction (RSEP), correlation coefficient $\left(\mathrm{R}^{2}\right)$ and adjusted correlation coefficient $\left(\mathrm{R}_{\text {adj }}^{2}\right)$.

General procedures: Basic yellow 28 (BY28) was supplied by the DyStar textile firm with the commercial name Astrazone Goldgelb GL-E. Potassium persulfate $\left(\mathrm{K}_{2} \mathrm{~S}_{2} \mathrm{O}_{8}\right)$ and ferrous sulfate $\left(\mathrm{FeSO}_{4} \cdot 7 \mathrm{H}_{2} \mathrm{O}\right)$ were obtained from Acros and Merck, respectively. The aqueous solutions were prepared in high purity de-ionized water (resistivity $18.2 \mathrm{~m} \Omega \mathrm{cm}$ ), which was obtained using a Milli-Q water purification system (Millipore). The basic yellow 28 stock solution was prepared at $1000 \mathrm{mg} / \mathrm{L}$. The desired concentration $\left(40 \mathrm{mg} \mathrm{L}^{-1}\right)$ of basic yellow 28 was obtained through the appropriate dilutions of the stock solution. The $\mathrm{K}_{2} \mathrm{~S}_{2} \mathrm{O}_{8}$ and $\mathrm{FeSO}_{4}$ solutions $(100 \mathrm{mM})$ were prepared prior to each batch experiment. However, the $\mathrm{FeSO}_{4}$ solution was prepared in acidic de-ionized water $(\mathrm{pH}$ 3.5).

The batch experiments for the decomposition of the basic yellow 28 solution were carried out in plugged borosilicate glass bottles. The initial concentration of basic yellow 28 was prepared as $40 \mathrm{mg} \mathrm{L}^{-1}$ from the stock solution. The $\mathrm{pH}$ was adjusted to 3.5 with $0.5 \mathrm{M} \mathrm{H}_{2} \mathrm{SO}_{4}$. The reaction solutions were obtained by adding the $\mathrm{FeSO}_{4}$ solution and the $\mathrm{K}_{2} \mathrm{~S}_{2} \mathrm{O}_{8}$ solution into the aqueous basic yellow 28 solutions with a total volume of $60 \mathrm{~mL}$. The mineralization experiments were conducted in a thermo-controlled $\left( \pm 1^{\circ} \mathrm{C}\right)$ water bath shaker at $120 \mathrm{rpm}$ at different temperatures $\left(40-70^{\circ} \mathrm{C}\right)$ in the range of 2 to $8 \mathrm{~h}$. The experiments were carried out in parallel. At the end of the reaction time, sodium azide was added to quench any further oxidation reactions. Subsequently, the aliquots of the samples were withdrawn from the reactor and filtered through a 0.45 $\mu \mathrm{m}$ membrane filter before the analysis.

Detection methods: The total organic carbon (TOC) contents of the aliquots were analyzed by using the Merck TOC cell test ( $\left.1.14878 .0001 / 5.0-80.0 \mathrm{mg} \mathrm{L}^{-1} \mathrm{TOC}\right)$. At the end of the reaction time, the sample aliquots were immediately filtered through a $0.45 \mu \mathrm{m}$ membrane. The TOC contents of the cell tests were measured by using the Merck Spectroquant NOVA 30 model photometer. 
TABLE-1

EXPERIMENTAL RESULTS OF BOX-BEHNKEN DESIGN EXPERIMENTS

\begin{tabular}{|c|c|c|c|c|c|c|}
\hline Run & $\mathrm{X}_{1}:\left[\mathrm{S}_{2} \mathrm{O}_{8}{ }^{2-}\right]_{0}$ & $\mathrm{X}_{2}:\left[\mathrm{Fe}^{2+}\right]_{0}$ & $\mathrm{X}_{3}: \mathrm{T}\left({ }^{\circ} \mathrm{C}\right)$ & $\mathrm{X}_{4}: \mathrm{t}(\mathrm{h})$ & $\begin{array}{l}\text { Observed TOC } \\
\text { removal }(\%)(\mathrm{Y})\end{array}$ & $\begin{array}{l}\text { Predicted TOC } \\
\text { removal }(\%)(\mathrm{Y})\end{array}$ \\
\hline 1 & $4(-1)$ & $1(-1)$ & $55(0)$ & $5(0)$ & 26 & 21 \\
\hline 2 & $12(+1)$ & $1(-1)$ & $55(0)$ & $5(0)$ & 64 & 65 \\
\hline 3 & $4(-1)$ & $3(+1)$ & $55(0)$ & $5(0)$ & 48 & 47 \\
\hline 4 & $12(+1)$ & $3(+1)$ & $55(0)$ & $5(0)$ & 43 & 47 \\
\hline 5 & $8(0)$ & $2(0)$ & $40(-1)$ & $2(-1)$ & 4 & 3 \\
\hline 6 & $8(0)$ & $2(0)$ & $70(+1)$ & $2(-1)$ & 57 & 54 \\
\hline 8 & $8(0)$ & $2(0)$ & $70(+1)$ & $8(+1)$ & 91 & 91 \\
\hline 9 & $4(-1)$ & $2(0)$ & $55(0)$ & $2(-1)$ & 16 & 16 \\
\hline 10 & $12(+1)$ & $2(0)$ & $55(0)$ & $2(-1)$ & 43 & 40 \\
\hline 11 & $4(-1)$ & $2(0)$ & $55(0)$ & $8(+1)$ & 65 & 68 \\
\hline 12 & $12(+1)$ & $2(0)$ & $55(0)$ & $8(+1)$ & 88 & 88 \\
\hline 13 & $8(0)$ & $1(-1)$ & $40(-1)$ & $5(0)$ & 23 & 25 \\
\hline 14 & $8(0)$ & $3(+1)$ & $40(-1)$ & $5(0)$ & 28 & 27 \\
\hline 16 & $8(0)$ & $3(+1)$ & $70(+1)$ & $5(0)$ & 69 & 67 \\
\hline 17 & $4(-1)$ & $2(0)$ & $40(-1)$ & $5(0)$ & 22 & 22 \\
\hline 18 & $12(+1)$ & $2(0)$ & $40(-1)$ & $5(0)$ & 42 & 40 \\
\hline 19 & $4(-1)$ & $2(0)$ & $70(+1)$ & $5(0)$ & 54 & 57 \\
\hline 20 & $12(+1)$ & $2(0)$ & $70(+1)$ & $5(0)$ & 81 & 82 \\
\hline 21 & $8(0)$ & $1(-1)$ & $55(0)$ & $2(-1)$ & 18 & 22 \\
\hline 22 & $8(0)$ & $3(+1)$ & $55(0)$ & $2(-1)$ & 21 & 24 \\
\hline 23 & $8(0)$ & $1(-1)$ & $55(0)$ & $8(+1)$ & 72 & 70 \\
\hline 24 & $8(0)$ & $3(+1)$ & $55(0)$ & $8(+1)$ & 79 & 76 \\
\hline 25 & $8(0)$ & $2(0)$ & $55(0)$ & $5(0)$ & 71 & 74 \\
\hline 26 & $8(0)$ & $2(0)$ & $55(0)$ & $5(0)$ & 75 & 74 \\
\hline 27 & $8(0)$ & $2(0)$ & $55(0)$ & $5(0)$ & 72 & 74 \\
\hline 28 & $8(0)$ & $2(0)$ & $55(0)$ & $5(0)$ & 77 & 74 \\
\hline 29 & $8(0)$ & $2(0)$ & $55(0)$ & $5(0)$ & 76 & 74 \\
\hline
\end{tabular}

The TOC removal \% was calculated according to the equation given below:

$$
\mathrm{TOC}_{\text {removal (\%) }}=\left[\frac{\mathrm{TOC}_{0}-\mathrm{TOC}_{\mathrm{t}}}{\mathrm{TOC}_{0}}\right] \times 100
$$

where, $\mathrm{TOC}_{0}$ and $\mathrm{TOC}_{\mathrm{t}}$ are the initial and final TOC $\left(\mathrm{mg} \mathrm{L}^{-1}\right)$ content values of the solution before and after the oxidative treatment, respectevily.

For the ammonium, nitrate and nitrite analysis, $2 \mathrm{~mL}$ samples were taken from the reaction bottles at the different time intervals. Next, methanol $(0.5 \mathrm{~mL})$ was added to quench any further oxidation reactions. The DIONEX ICS 3000 Dual model ion chromatograph equipped with a conductivity detector, an AS9-HC, $4 \mathrm{~mm} \times 250 \mathrm{~mm}$ anion-exchange and CS12A 4 $\mathrm{mm} \times 250 \mathrm{~mm}$ cation-exchange columns were used to measure the inorganic ions. The mobile phase was a solution of: sodium carbonate $(10 \mathrm{mM})$ and a total flow rate of $1.0 \mathrm{~mL} / \mathrm{min}$ for the anion analysis, meta-sulfonic acid $(0.02 \mathrm{~N})$ and a total flow rate of $1.0 \mathrm{~mL} / \mathrm{min}$ for the cation analysis.

The GC-MS analysis was performed with the 5890A Agilent model gas chromatograph, interfaced with the ECD, NPD and 5975C mass selective detector. The aqueous solutions were extracted three times with $50 \mathrm{~mL}$ dichloromethane. A $3 \mathrm{~mL}$ sample was analyzed on GC-MS. The analytical column, which was connected to the system, was an HP5-MS capillary column $(30 \mathrm{~m} \times 0.25 \mathrm{~mm} \times 0.25 \mu \mathrm{m})$. Helium was used as the carrier gas with a flow rate of $2 \mathrm{~mL} / \mathrm{min}$. The $\mathrm{GC}$ injection port temperature was $250^{\circ} \mathrm{C}($ split mode $=1 / 5)$ and the column temperature was fixed at $70{ }^{\circ} \mathrm{C}$ for $5 \mathrm{~min}$. Subsequently, the column temperature was programmed from 70 to $150{ }^{\circ} \mathrm{C}$ at $4{ }^{\circ} \mathrm{C} / \mathrm{min}$ and then from 150 to $280^{\circ} \mathrm{C}$ with the $5^{\circ} \mathrm{C} / \mathrm{min}$ rate. The MS detector was operated in the EI mode $(70 \mathrm{eV})$.

\section{RESULTS AND DISCUSSION}

Evaluation of experimental results with design-expert: A set of four process variables, the operating temperature (40$70{ }^{\circ} \mathrm{C}$ ), the $\mathrm{K}_{2} \mathrm{~S}_{2} \mathrm{O}_{8}$ initial concentration (4-12 mM), the $\mathrm{FeSO}_{4}$ initial concentration (1-3 $\mathrm{mM})$ and processing time (2-8 $\mathrm{h}$ ) were identified to investigate their influences on the TOC removal \% of basic yellow 28 at initial $\mathrm{pH} 3.5$. These intervals were determined as a result of preliminary experiments. When the dye solutions were mixed with various ion concentrations of $\mathrm{S}_{2} \mathrm{O}_{8}{ }^{2-}$ and the $\mathrm{Fe}^{2+}$, the dye immediately started to degrade. The reaction intermediates can occur during the oxidation of the target compounds. It is possible that some of the intermediate products are more toxic and long-lived than starting compounds during decomposition. Therefore, it is important to monitor the contents of the TOC in various stages of treatment. Mineralization of the treated basic yellow 28 solutions during the $\mathrm{S}_{2} \mathrm{O}_{8}{ }^{2-} / \mathrm{Fe}^{2+}$ oxidative treatment was followed by measuring the total organic carbon (TOC). For the above mentioned four variables, a set of 29 experiments is required (Table-1). BoxBehnken design is a spherical, revolving design. It consists of five replicates central point $\left(\mathrm{C}_{\mathrm{p}}\right)$ and the edge points are located on a hypersphere equidistant from $\mathrm{C}_{\mathrm{p}}$. Calculate the number of necessary experiments number is made according to the following 
formula: $\mathrm{N}=2 \mathrm{k}(\mathrm{k}-1)+\mathrm{C}_{\mathrm{p}}$, where $\mathrm{k}$ is the number of factors and $C_{p}$ is the number of the central points. The experimental results obtained in the Box-Behnken design with the real and coded values for the four variables studied are shown in Table-1.

In an aqueous medium, the individual and interactive effects of the setted four variables on the mineralization of the basic yellow 28 dye in an aqueous medium were investigated using the Box-Behnken design application. The experimental results were evaluated with RSM of Design-Expert ${ }^{\circledR} 8$. The approximating functions of the TOC removal percent (Y) in terms of the coded variables obtained are shown as follows:

$$
\begin{aligned}
& Y=74.20+10.83 X_{1}+2.00 X_{2}+19.33 X_{3}+24.83 X_{4}-10.75 X_{1} X_{2}+ \\
& 1.75 X_{1} X_{3}-1.00 X_{1} X_{4}+0.75 X_{2} X_{3}+1.00 X_{2} X_{4}-6.00 X_{3} X_{4}- \\
& 12.14 X_{1}^{2}-17.14 X_{2}^{2}-11.89 X_{3}^{2}-9.14 X_{4}^{2}
\end{aligned}
$$

Fig. 1 provides Pareto graphic analysis, respectively. These analyses introduce single or synenergistic positive or inimical effects of variables on the studied response ${ }^{30}$. Pareto graphic analysis based on the following formula gives the percentage effects of each factor on the response.

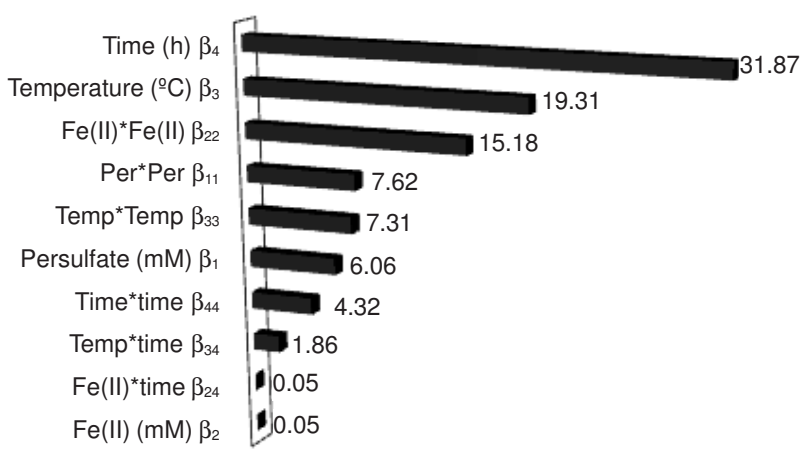

Fig. 1. Graphical pareto analysis

$$
P i=\left(\frac{\beta_{i}^{2}}{\sum \beta_{i}^{2}}\right) \times 100(i \neq 0)
$$

It is demonstated that the processing time $\left(\beta_{4}\right)$, temperature $\left(\beta_{3}\right)$ and persulfate ion initial concentration $\left(\beta_{1}\right)$ are the crucial factors for the mineralization of basic yellow 28 . However, the ferrous ion initial concentration $\left(\beta_{2}\right)$ has a slight influence on the oxidation. Analysis of variance and regression takes place in almost all statistical studies. The relationships between an unlimited number of independent variables and a response or dependent variable are investigated by regression. Regression also allows values on one variable to be predicted from the values recorded on one or more other variables. In the same way, ANOVA places no restriction on the number of groups or conditions that may be compared, while factorial ANOVA allows examination of the influence of two or more independent variables or factors on a dependent variable with t-test statistics in the program for eqn. 6 . As a result of the experimental data quadratic model was determined as statistically significant. The quadratic regression model was highly significant as the F-test (F-value) was found to be 101.16 with a very low probability value ( $\mathrm{P}$-value $<0.0001)$. This indicated that only $0.01 \%$ of the model was due to noise ${ }^{31}$. If the model has a high degree of adequacy to predict of the experimental results, the computed F-value should be greater than the tabulated F-value at a level of significance $\alpha$. Therefore, the calculated F-value $\left(\mathrm{F}_{\text {model }}=101.16\right)$ was compared with the tabulated $\mathrm{F}$-value $\left(\mathrm{F}_{0.05, \mathrm{df},(\mathrm{n}-(\mathrm{df}+1))}\right)$ at significance level of 0.05, when the df for model is 14 and $n=29$. The Tabular F-value $\left(\mathrm{F}_{0.05,14,14}=2.48\right)$ is clearly less than calculated $\mathrm{F}$ value $^{20}$.

To test the fit between the model responses and the observed data is performed chi-square $\left(\mathrm{X}^{2}\right)$ test. This value was computed by the following equations ${ }^{20}$ :

$$
\text { Chi-Square }=\sum_{\mathrm{i}=1}^{\mathrm{N}} \frac{\left(\mathrm{Y}_{\text {meas }, \mathrm{i}}-\mathrm{Y}_{\text {pred }, \mathrm{i}}\right)^{2}}{\mathrm{Y}_{\text {pred,i }}}
$$

where $Y_{\text {pred,i }}$ and $Y_{\text {meas,i }}$ are the model predicted and measured values of the variable, $\mathrm{Y}$ and $\mathrm{N}$ is the number of run.

The calculated chi-square value of the model $\left(X^{2}=4.60\right)$ was found to be less than the tabulated value $\left(\mathrm{X}_{0.05}^{2}=41.34\right)$. This result revealed that there is not a significant difference between the observed data and model response. The quality of the fit of the polynomial model was also expressed by the determination of correlation coefficient, $\mathrm{R}^{2}$ and the adjusted coefficient $\mathrm{R}_{\text {adj. }}^{2}$ The correlation between the experimental data and predicted responses is explained by the value of $\mathrm{R}^{2}$. The obtained values of $\mathrm{R}^{2}$ and $\mathrm{R}^{2}$ adj were 0.9902 and 0.9804 , respectively. The adjusted $R^{2}\left(R_{\text {adj }}^{2}\right)$ value is more suitable to compare the models with different numbers of the independent variables. R squared estimates the proportion of the dependent variable variance that can be attributed to the predictors, but unfortunately this statistic exhibits an overestimate bias. The smaller adjusted $\mathrm{R}$ squared attempts to eliminate this bias ${ }^{32}$. As shown Fig. 2(a), the correlation coefficient $\left(R^{2}\right)$ between the experimental and model predicted values of the response variable showed the goodness of fit of the model. A plot of the normal probability of the residuals is shown in Fig. 2(b). The residuals from the analysis should be normally distributed. The above mentioned plot is an important diagnostic tool to detect and explain the systematic departures from the assumption $^{33}$. The trend of the residual to a normal distribution, where the errors are normally distributed and independent of each other is shown in Fig. 2(b) In addition, the error variance is homogeneous. Signal to noise ratio is measured by "Adeq Precision" which value should be grater than 4 . The ratio of 35.60 indicates an adequate signal. Fig. 2(c) displays a plot of residuals versus predicted response that provides a handy diagnostatic for nonconstant variance. In this case, the pattern exhibits the hoped-for random scatter, suggesting the variance of original observations is constant for all values of the response.

An effective tool for checking lurking variables that may have influenced the response during the experiment is the normal plot of the standardized residuals versus the experimental run number as shown in Fig. 2(d). The plot should show a random scatter around the center line and within the interval of \pm 3.50 . Trends indicate a time-related variable lurking in the background. Blocking and randomization provide insurance against trends ruining the analysis ${ }^{34}$. As a result, Fig. 2(d) represents that there was no apparent deviation with the observation order $( \pm 3.00)$. 

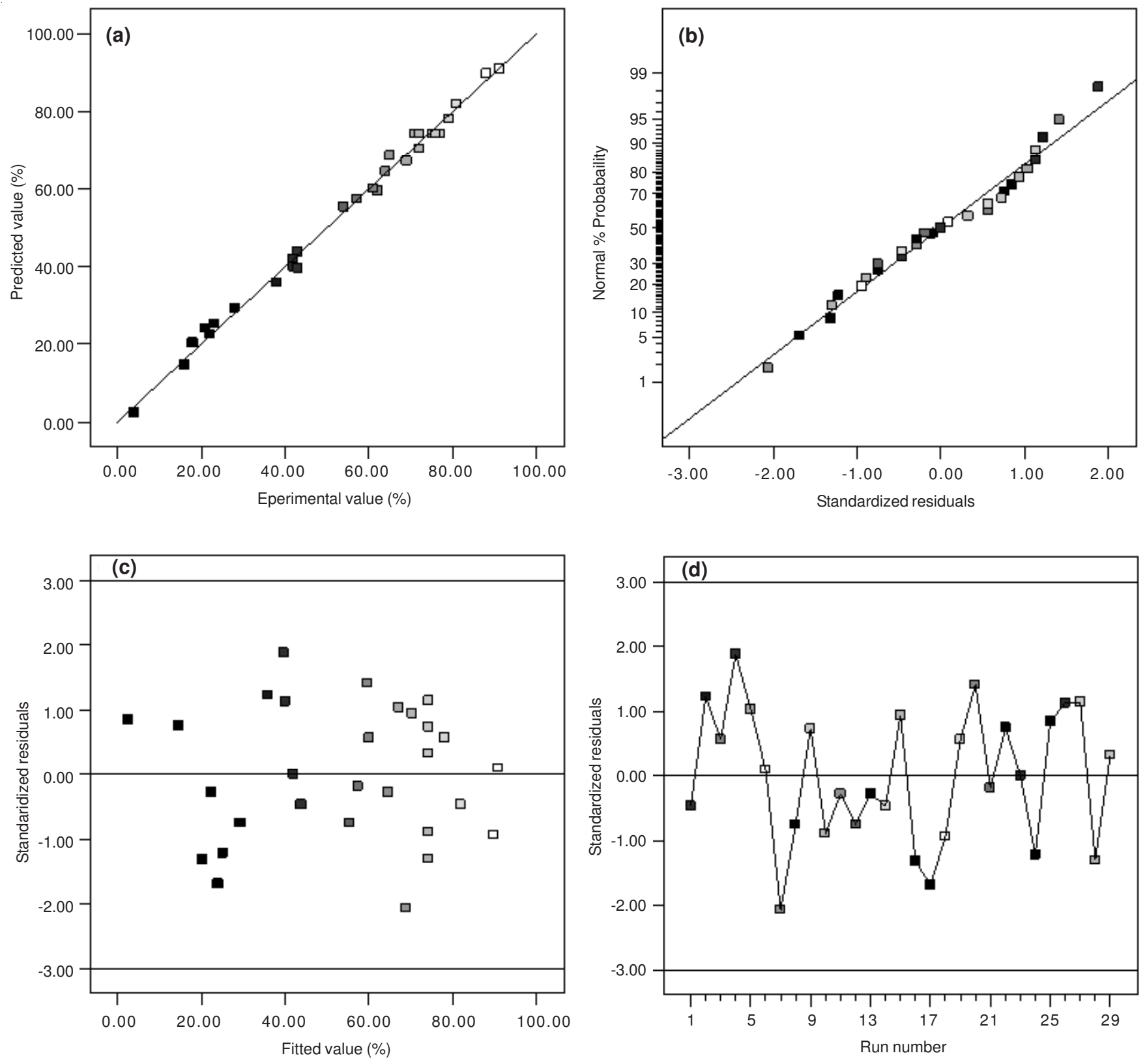

Fig. 2. (a) The actual and predicted plot of TOC removal percent $\left(R^{2}=0.9902\right.$ and $\left.R_{\text {adj }}^{2}=0.9804\right)$, (b) the standardized residual and normal $\%$ probability plot of TOC removal per cent, (c) the predicted TOC removal per cent and standardized residuals plot, (d) the standardized residuals plot for TOC removal efficiency

Effects of variables in the three-dimensional response surface plots: The contour plot and the corresponding 3D view for the initial persulfate ion concentration versus the initial ferrous ion concentration, while holding temperature at $65^{\circ} \mathrm{C}$ and time $8 \mathrm{~h}$ is shown in Fig. 3(a). It is well established that persulfate plays an important role as a source of $\mathrm{SO}_{4}{ }^{-}$ production in the $\mathrm{S}_{2} \mathrm{O}_{8}{ }^{2-} / \mathrm{Fe}^{2+}$ oxidative treatment. In the present study, various initial concentrations of $\mathrm{S}_{2} \mathrm{O}_{8}{ }^{2-}$ in the range of 4 and $12 \mathrm{mM}$ were used for the mineralization of the basic yellow 28 dye in an aqueous solution to obtain its optimal concentration. The TOC removal per cent values showed fast increase due to an increase of the initial persulfate concentration to $10 \mathrm{mM}$, especially $\mathrm{Fe}^{2+}$ concentration in the range of 1.5-2.25 mM. The TOC removal percentage value reached $96 \%$ at the end of the $8 \mathrm{~h}$ experiments, while the persulfate concentration was $9.7 \mathrm{mM}$ at $\left[\mathrm{Fe}^{2+}\right]_{0}=2 \mathrm{mM}$. However, an increase of the persulfate concentration beyond $10 \mathrm{mM}$ resulted in a decrease in the mineralization efficiency. Regarding the effect of iron appears to have been achieved the best results around $2 \mathrm{mM}$. If the concentration of $\mathrm{Fe}$ (II) is less than 1.5 and higher than $2.5 \mathrm{mM}$, the TOC removal percents may decrease.

Temperature is one of the main parameters which influence the production of $\mathrm{SO}_{4}{ }^{--}$in the oxidative processes based on persulfate. In Fig. 3(b), the response surface and contour plots show that obtained TOC removal (\%) values as a function of the initial persulfate concentration and reaction temperature, keeping the initial concentration of $\mathrm{Fe}^{2+}$ at $2 \mathrm{mM}$ and time at 8 h. It can clearly be observed that a rise in the temperature is significantly effective on the removal of basic yellow 28 . When 
the effects of the temperature and persulfate concentration on TOC removal were investigated, the effective temperature and persulfate concentration intervals were obtained as $55-65^{\circ} \mathrm{C}$ and 8-10 mM, respectively. The effect of time and concentration of $\mathrm{Fe}$ (II) on the TOC removal is shown in Fig. 3(c). The highest TOC removal data was obtained when the concentration of Fe(II) was hold around $2 \mathrm{mM}$. Fig. 3(d) shows the TOC removal per cent at the mentioned range of time and temperature, keeping the initial concentration of $\mathrm{Fe}^{2+}$ at $2 \mathrm{mM}$ and persulfate at $8 \mathrm{mM}$. An increase in TOC conversion with both time and temperature was observed. This tendency can be explained as follows: based on a previously described freeradical involved reaction mechanism, the concentration of free radicals increases with temperature and then enhances the organic compounds degradation. Fig. 3(d) is examined, when the amount of $\mathrm{Fe}(\mathrm{II})$ is kept around $2 \mathrm{mM}$, the results show that the temperature should be adjusted over $60{ }^{\circ} \mathrm{C}$ and the time should be over $6.5 \mathrm{~h}$.

Oh et al. obtained that the rate of poly (vinyl alcohol) (PVA) $\left(50 \mathrm{mg} \mathrm{L}^{-1}\right.$ ) oxidation was maximized when the persulfate to $\mathrm{Fe}^{2+}$ molar ratio was $1: 1$ at $20^{\circ} \mathrm{C}\left(250 \mathrm{mg} \mathrm{L}^{-1} \mathrm{~K}_{2} \mathrm{~S}_{2} \mathrm{O}_{8}=0.92\right.$ $\left.\mathrm{mMK}_{2} \mathrm{~S}_{2} \mathrm{O}_{8}\right)^{24}$. They also observed that increasing the temperature from 20 to $80^{\circ} \mathrm{C}$ accelerated the oxidation rate of poly(vinyl alcohol), at these temperatures degradation of poly(vinyl alcohol) was completed 120 and $30 \mathrm{~min}$, respectively. But, TOC removal of poly(vinyl alcohol) in the experiments has not been followed. Li et al. also investigated the effect of $\mathrm{pH}$, persulfate concentration, ionic strength, temperature and catalytic $\mathrm{Fe}^{3+}$ and $\mathrm{Ag}^{+}$on the degradation efficiency of diphenylamine (DPA) by persulfate in batch experiments ${ }^{25}$. They observed that $\mathrm{Ag}^{+}$ion is more efficient than $\mathrm{Fe}^{3+}$ ion and the increase of either the $\mathrm{pH}$ value or ionic strength caused those inhibitive effects on the degradation of diphenylamine $(20 \mu \mathrm{g}$ $\left.\mathrm{mL}^{-1}\right)$. Their results showed that the rate of diphenylamine degradation increased as the initial persulfate concentration increased in the range of 4.4 to $33 \mathrm{mM}$. Nfodzo and Choi ${ }^{26}$ has also investigated degradation of triclosan by using persulfate/ $\mathrm{Ag}^{+}$ion. They found that an oxidant: metal molar ratio of 1:1 (stoichiometric amount) was not an optimum for degradation of this substance. As a result, it is reported that the reactivity of oxidant/metal systems to be depending on the target compound. In another study ${ }^{7}$, an azo dye orange $\mathrm{G}$ (OG) was degraded by the persulfate/ferrous system at $\mathrm{pH}$ 3.5. Batch experiments were performed in $50 \mathrm{~mL}$ test tubes. In the above mentioned study it was observed that at $\left[\mathrm{Fe}^{2+}\right]=$ $1 \mathrm{mM}$, increasing the dosage of persulfate from 1 to $4 \mathrm{mM}$
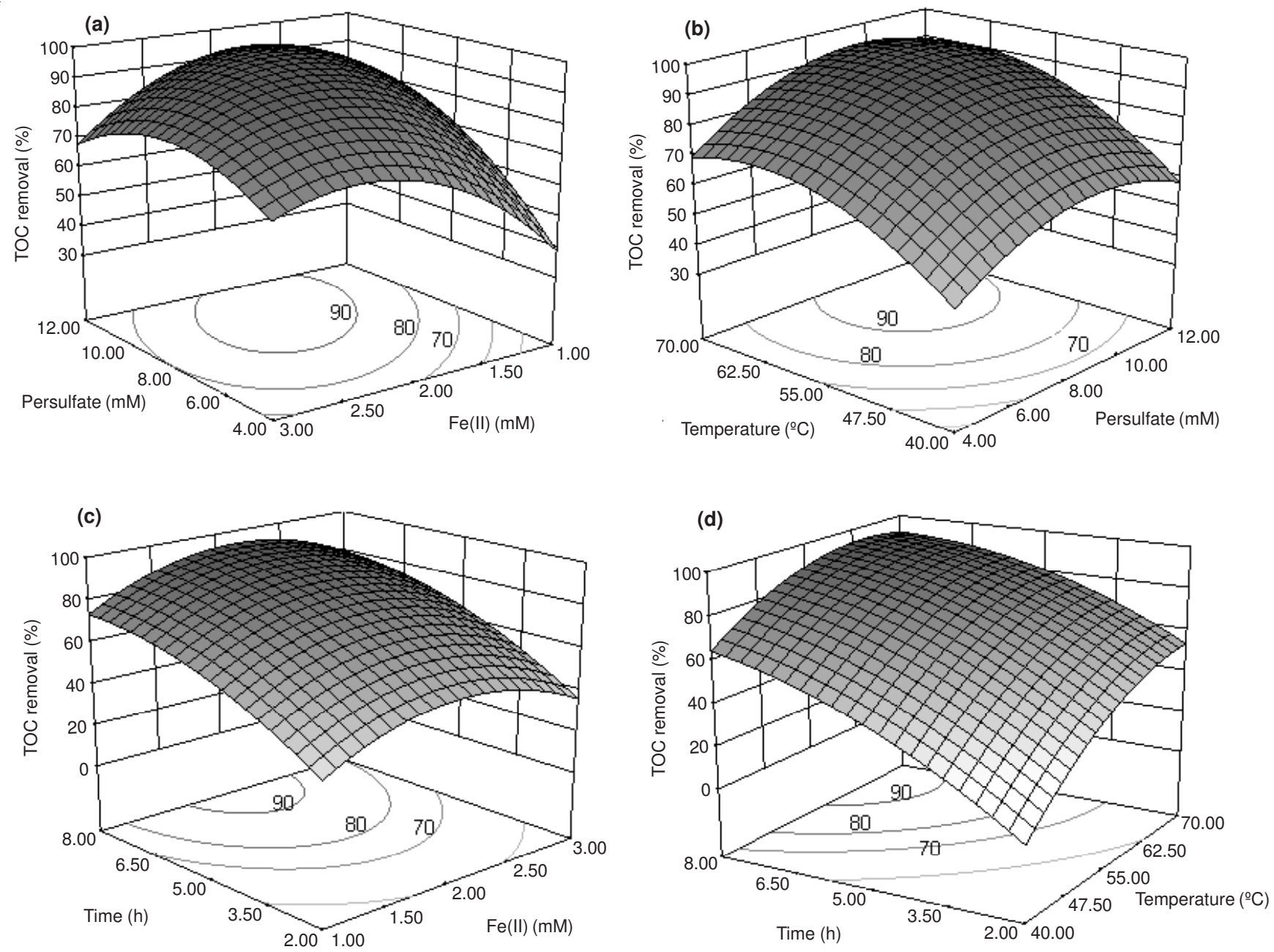

Fig. 3. The effect of (a) initial persulfate and ferrous ion concentrations $\left(\mathrm{T}=65^{\circ} \mathrm{C}, \mathrm{t}=8 \mathrm{~h}\right)$, (b) temperature and persulfate concentration $\left(\left[\mathrm{Fe}^{2+}\right]_{0}=2 \mathrm{mM}, \mathrm{t}=8 \mathrm{~h}\right),(\mathrm{c})$ time and ferrous ion concentrations $\left(\mathrm{T}=65^{\circ} \mathrm{C},\left[\mathrm{S}_{2} \mathrm{O}_{8}{ }^{2-}\right]_{0}=8 \mathrm{mM}\right),(\mathrm{d})$ time and temperature $\left(\left[\mathrm{Fe}^{2+}\right]_{0}=2\right.$ $\mathrm{mM},\left[\mathrm{S}_{2} \mathrm{O}_{8}{ }^{2-}\right]_{0}=8 \mathrm{mM}$ ) on TOC removal 
([Persulfate $] /\left[\mathrm{Fe}^{2+}\right]=$ from $1: 1$ to $4: 1$ ) resulted in an increase orange $\mathrm{G}$ degradation. When $\mathrm{Fe}^{2+}$ concentration varied from 0.5 to $4 \mathrm{mM}$ (persulfate concentration is kept constant as 4 $\mathrm{mM}$ ), the efficiency of orange $\mathrm{G}$ degradation was increased from 54 to $99 \%$ within $0.5 \mathrm{~h}$. In this study, the optimum conditions for orange $\mathrm{G}$ degradation was found as persulfate at 4 $\mathrm{mM}$ and ferrous ion at $4 \mathrm{mM}$ at $\mathrm{pH} 3.5$ and $20^{\circ} \mathrm{C}$. However, with a further increase of the $\mathrm{Fe}^{2+}$ concentration up to $8 \mathrm{mM}$, orange $\mathrm{G}$ degradation reduced ${ }^{7}$. The above mentioned tendency explained that the ferrous ion can also act as a sulfate radical scavenger at its high concentration, according to eqn. 10.

$$
\mathrm{Fe}^{2+}+\mathrm{SO}_{4}{ }^{--} \rightarrow \mathrm{Fe}^{3+}+\mathrm{SO}_{4}{ }^{2-} \quad\left(\mathrm{k}=3.0 \times 10^{8} \mathrm{M}^{-1} \mathrm{~s}^{-1}\right)(10)
$$

The optimum conditions obtained in the present study differs from others may be due to differences both target compound and experimental conditions. In addition to the previous studies the effects of four variables alone or interaction on basic yellow 28 degradation has been examined with the RSM in the present study. The negative effect of the ferrous ion was determined over the $2.5 \mathrm{mM}$ Fe(II) value. The sulfate radicals were also consumed by some other reactions ${ }^{35-37}$ :

$$
\begin{gathered}
\mathrm{SO}_{4}{ }^{--}+\mathrm{H}_{2} \mathrm{O} \rightarrow \mathrm{OH}^{\bullet}+\mathrm{HSO}_{4}^{-}\left(\mathrm{k}=500 \mathrm{~s}^{-1}\right) \\
\mathrm{SO}_{4}{ }^{--}+\mathrm{SO}_{4}^{--} \rightarrow 2 \mathrm{SO}_{4}{ }^{-}-\left(\mathrm{k}=8.9 \times 10^{8} \mathrm{M}^{-1} \mathrm{~s}^{-1}\right) \\
\mathrm{SO}_{4}{ }^{--}+\mathrm{OH}^{\bullet} \rightarrow \mathrm{HSO}_{4}^{-}+1 / 2 \mathrm{O}_{2} \\
\mathrm{OH}^{\bullet}+\mathrm{OH}^{\bullet} \rightarrow \mathrm{H}_{2} \mathrm{O}_{2} \quad\left(\mathrm{k}=5.2 \times 10^{9} \mathrm{M}^{-1} \mathrm{~s}^{-1}\right) \\
\mathrm{SO}_{4}{ }^{--}+\mathrm{H}_{2} \mathrm{O}_{2} \rightarrow \mathrm{HO}_{2}{ }^{-}+\mathrm{H}^{+}+\mathrm{SO}_{4}{ }^{2-}\left(\mathrm{k}=1.2 \times 10^{7} \mathrm{M}^{-1} \mathrm{~s}^{-1}\right) \\
\mathrm{SO}_{4}{ }^{--}+\mathrm{S}_{2} \mathrm{O}_{8}{ }^{2-} \rightarrow \mathrm{S}_{2} \mathrm{O}_{8}{ }^{-}+\mathrm{SO}_{4}{ }^{2-}\left(\mathrm{k}=6.1 \times 10^{5} \mathrm{M}^{-1} \mathrm{~s}^{-1}\right)
\end{gathered}
$$

In work of Gozmen and Turabik, the degradation of basic yellow 28 at the same concentration was performed by UV/ $\mathrm{TiO}_{2} / \mathrm{IO}_{4}^{-}$system and was obtained $85 \%$ of mineralization after $3 \mathrm{~h}$ treatment at $\mathrm{pH} 5.2\left(\left[\mathrm{IO}_{3}^{-}\right]=5 \mathrm{mM}\right)^{38}$. However, the obtained mineralization values of this study are lower than in the previous study. It could be said that persulfate/ $\mathrm{Fe}^{2+}$ system is not very effective on the degradation of basic yellow 28 dye, but it can be thought of as environmentally friendly and more economical.

It is also established that the TOC removal decreases with the $\mathrm{Fe}^{3+}$ and/or $\mathrm{Fe}^{2+}$ ions in the solution because of the formation of Fe ions complexes with carboxylic acids and the degradation products ${ }^{39}$. To understand the combined effect of $\mathrm{S}_{2} \mathrm{O}_{8}{ }^{2-} / \mathrm{Fe}^{2+}$, the experiments were conducted with the use of $\mathrm{Fe}^{2+}$ and $\mathrm{S}_{2} \mathrm{O}_{8}{ }^{2-}$ alone. However, the TOC removal was not achieved in the above mentioned experiments.

Optimization of the removal of dye: The experimental results were optimized by Design-Expert software using the approximating function of basic yellow 28 removal percent in eqn. 7. Desirability is an objective function that ranges from zero outside of the limits to one at the goal. The simultaneous objective function is a geometric mean of all transformed responses:

$$
D=\left(d_{1} \times d_{2} \times \ldots \times d_{n}\right)^{\frac{1}{n}}=\left(\prod_{i=1}^{n} d_{i}\right)^{\frac{1}{n}}
$$

The $d_{i}$, which ranges from 0 to 1 (the least to most desirable, respectively), conceives the desirability of each individual (i) response and the number of responses being optimized is $\mathrm{n}^{34}$.

The numerical optimization finds a point that maximizes the desirability function. The characteristics of a goal may be altered by adjusting the weight or importance. For several responses and factors, all goals get combined into one desirability function. The possible goals are: maximize, minimize, target, within range, none (for responses only) and set to an exact value (factors only) ${ }^{40}$. In this study, all factors was in the range of experimental design value, whereas removal of basic yellow 28 were maximized. Fig. 4 shows the TOC removal $\%$ values in the end of the maximization study for the basic yellow 28 removal per cent (between 85 and $100 \%$ ) with the desirability value of 1 depending on the selected goal for the variables. Optimal conditions were chosen as persulfate at $9.87 \mathrm{mM}$ and ferrous ion at $1.95 \mathrm{mM}$, time at $8 \mathrm{~h}$ and temperature at $65^{\circ} \mathrm{C}$ to avoid spending excess persulfate and ferrous ions for 40 $\mathrm{mg} \mathrm{L}^{-1}$ basic yellow 28 at $\mathrm{pH}$ 3.5. The optimal parameter values were validated through persulfate/ferrous oxidation experiments. As a result of confirmatory experiments are performed by using the optimal conditions and closely results (93\%) was obtained with the data from optimization analysis using desirability function.

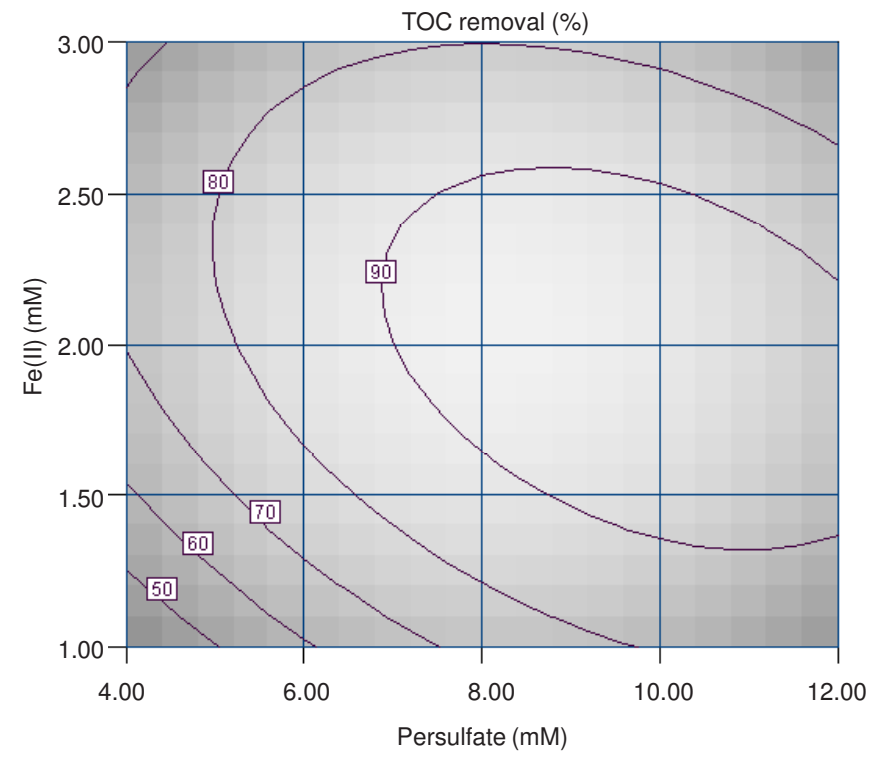

Fig. 4. The maximize TOC removal $\%$ values with desirability value of 1 (between 85 and $100 \%$ )

Identification of intermediates: A solution $40 \mathrm{mg} \mathrm{L}^{-1}$ of basic yellow 28 was treated for 20,60, 180 and 300 min at $65{ }^{\circ} \mathrm{C}$. The remaining organics were extracted for the analysis of GC-MS. The hydroxyl radical and sulfate radical anion are powerful oxidants, which can degrade the organic molecules at a faster rate ${ }^{41}$. The degradation reaction of a dye can be written as follows:

$$
\begin{gathered}
\text { Dye }+\mathrm{OH}^{\bullet} \rightarrow \text { degradation product } \\
\text { Dye }+\mathrm{SO}_{4}{ }^{\bullet-} \rightarrow \mathrm{Dye}^{\bullet-}+\mathrm{SO}_{4}{ }^{2-}
\end{gathered}
$$

The direct degradation of basic yellow 28 using $\mathrm{S}_{2} \mathrm{O}_{8}{ }^{2-}$ may be ignored, because of no detectable degradation was observed after $1 \mathrm{~h}$ treatment at room temperature. The aromatic 


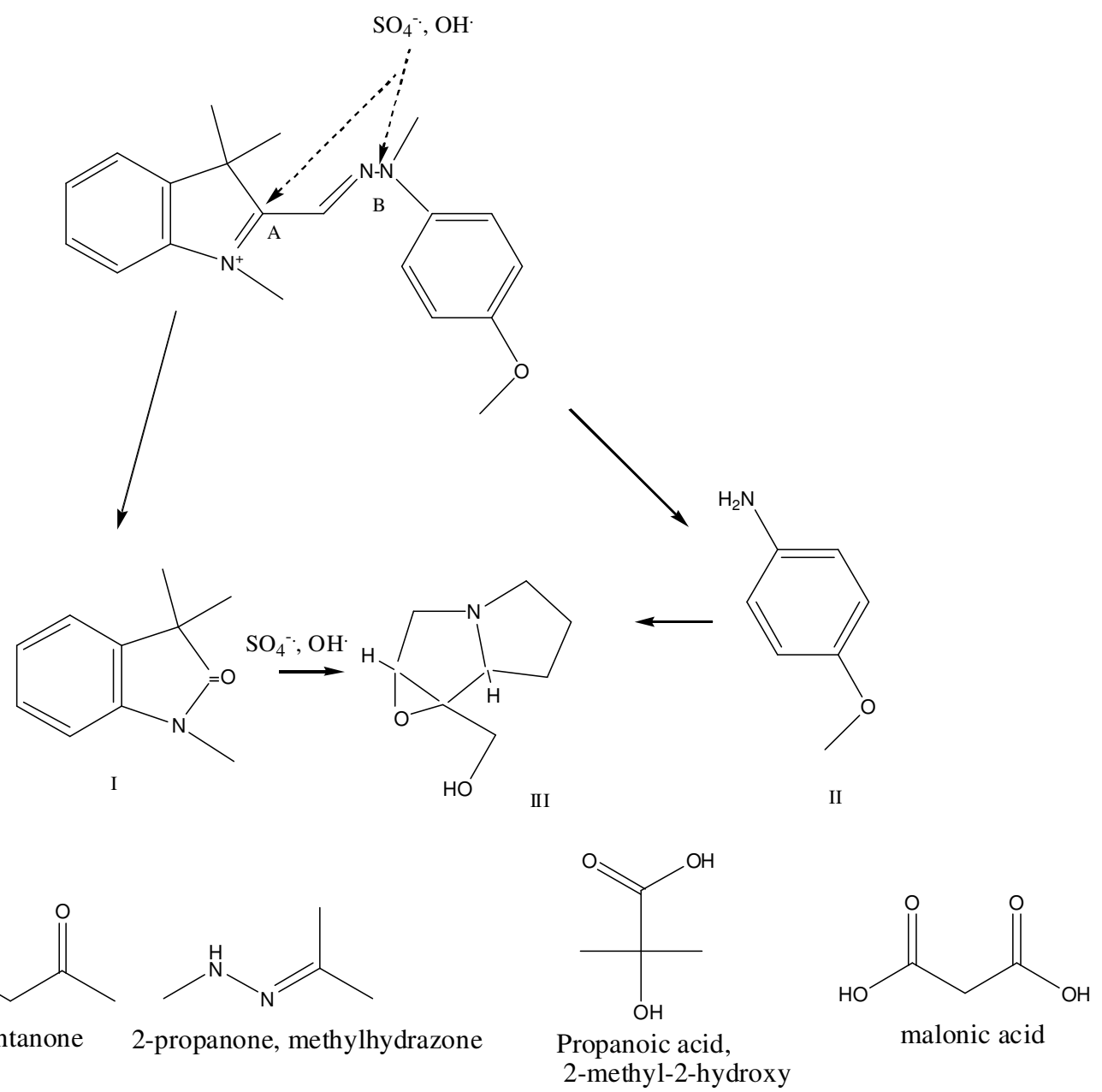

Fig. 5. Proposed reaction scheme for the initial degradation of basic yellow 28 by persulfate/ferrous oxidation

oxidation reaction intermediates identified at the early stage (after $20 \mathrm{~min}$ for $65^{\circ} \mathrm{C}$ ) of the $\mathrm{S}_{2} \mathrm{O}_{8}{ }^{2-} / \mathrm{Fe}^{2+}$ treatment may indicate that the degradation pathway was initiated by two possible paths. This was due to the oxidative attack of the radicals. The probable pathway can be described by Fig. 5. As the observed structures of I and III, it can be said that the main attack of the radicals materialized to regions of $\mathrm{A}$ and $\mathrm{B}$, which contain the double bond. On the one hand, 2-indolinone 1,3,3,trimethyl (I) comes from the hydroxyl radical attack on A region, while on the other hand benzenamine-4-methoxy (II) comes from the cleavage of the $\mathrm{N}-\mathrm{N}(-\mathrm{C}=\mathrm{N}-\mathrm{N})$ bond ( $\mathrm{B}$ region). The supinidine, 1- $\beta, 2-\beta$,-epoxy (III) can form from the hydroxylation of (I). Then, oxidative ring opening reactions lead to formation of small structures such as 2-pentanone $\left(\mathrm{M}^{+}\right.$: 86), 2-propanone, methylhydrazone $\left(\mathrm{M}^{+}: 86\right)$, 2-pentanone $\left(\mathrm{M}^{+}\right.$: 86), malonic acid $\left(\mathrm{M}^{+}: 104\right)$ and propanoic acid, 2methyl-2-hydroxy $\left(\mathrm{M}^{+}: 104\right)$ (detected at before $\left.5 \mathrm{~min}\right)$. After the attack on the $\mathrm{B}$ region by the radicals, the nitrogen element departed from the aqueous phase as $\mathrm{NO}_{3}{ }^{-}, \mathrm{NO}_{2}^{-}$or $\mathrm{NH}_{4}{ }^{+}$. In the basic yellow 28 dye structure, basic yellow 28 absorbance value at $438 \mathrm{~nm}$ was not observed due to the conjugated chromophore group is broken in the oxidative degradation process. This signifies the removal of the dye.

Mineralization of basic yellow 28 leads to the conversion of the nitrogen and sulfur heteroatoms present in the molecule into inorganic ions, such as nitrate, nitrite, ammonium and sulfate ions. The evolution of these inorganic ions monitored by the ion chromatography analyses at $65^{\circ} \mathrm{C}$ during the treatments is shown in Fig. 6.

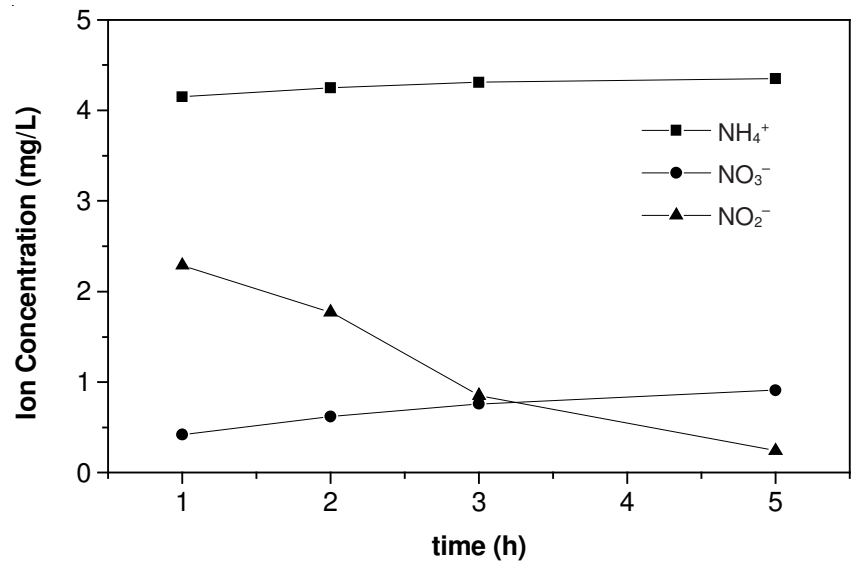

Fig. 6. Time course of inorganic ions produced during mineralization of $40 \mathrm{mg} / \mathrm{L}$ basic yellow 28 aqueous solution $\left(\left[\mathrm{S}_{2} \mathrm{O}_{8}{ }^{2-}\right]_{0}=9.87 \mathrm{mM}\right.$, $\left(\left[\mathrm{Fe}^{2+}\right]_{0}=2 \mathrm{mM}, \mathrm{T}=65^{\circ} \mathrm{C}\right)$

At the beginning of the oxidation process nitrite ion concentration is seen to be more than the nitrate. However, the nitrite ion concentration dropped quickly and reached 0.2 $\mathrm{mg} \mathrm{L}^{-1}$ after $5 \mathrm{~h}$. The nitrate ions showed a slow rise during the $5 \mathrm{~h}$ up to $1 \mathrm{mg} \mathrm{L}^{-1}$ concentration. The nitrate concentration 
remained stable at $4.2 \mathrm{mg} \mathrm{L}^{-1}$ after $2 \mathrm{~h}$. Hence, the sulfate ions formed from sources other than the dye molecule were not measured.

\section{Conclusion}

Degradation and mineralization of $40 \mathrm{mg} \mathrm{L}^{-1}$ of the basic yellow 28 aqueous solution by the $\mathrm{S}_{2} \mathrm{O}_{8}{ }^{2-} / \mathrm{Fe}^{2+}$ system at $\mathrm{pH}$ 3.5 was studied as a function oxidation time, temperature and initial concentration of $\mathrm{Fe}^{2+}$ and $\mathrm{S}_{2} \mathrm{O}_{8}{ }^{2-}$. The application of the Box-Benkhen design combined with the response surface modeling and optimization helped in attaining the optimal solution of reaching the maximum basic yellow 28 degradation in an aqueous solution by the $\mathrm{S}_{2} \mathrm{O}_{8}{ }^{2-} / \mathrm{Fe}^{2+}$ system. The optimum conditions were satisfied as $8 \mathrm{~h}$ treatment at $65^{\circ} \mathrm{C}$ reaction temperature; $9.87 \mathrm{mM}$ persulfate initial concentration and 1.95 $\mathrm{mM}$ ferrous ion concentration; thereby realizing $93 \%$ TOC removal per cent. It was demonstrated that the basic yellow 28 structure is broken down into two main aromatic intermediates early in the process. To reach a TOC removal percent of $93 \%$, it was observed that the above mentioned aromatic structures underwent a ring opening as well as the occurrence of smaller structures, such as organic carboxylic acids.

\section{ACKNOWLEDGEMENTS}

The authors are grateful to the Mersin University Research Found (contract no: BAB-FEF KB (BG) 2010-4A) for the financial support and Mersin University Research and Application Center (MEITAM) for providing the facilities at the GC-MS and ion chromatography analysis.

\section{REFERENCES}

1. O.J. Hao, H. Kim and P.C. Chang, Crit. Rev. Environ. Sci. Technol., 30, 449 (2000).

2. S.F. Li, Bioresour. Technol., 101, 2197 (2010).

3. K.C. Huang, R.A. Couttenye and G.E. Hoag, Chemosphere, 49, 413 (2002).

4. C. Liang, C.J. Bruell, M.C. Marley and K.L. Sperry, Chemosphere, 55, 1213 (2004).

5. G.P. Anipsitakis and D.D. Dionysiou, Appl. Catal. B, 54, 155 (2004).

6. T.K. Lau, W. Chu and N.J.D. Graham, Environ. Sci. Technol., 41, 613 (2007).

7. X.R. Xu and X.Z. Li, Sep. Purif. Technol., 72, 105 (2010)

8. L. Eberson, Electron Transfer Reactions in Organic Chemistry, Springer-Verlag, Berlin (1987).

9. I.M. Kolthoff, A.I. Medalia and H.P. Raaen, J. Am. Chem. Soc., 73, 1733 (1951).

10. C. Liang, Z.S. Wang and C.J. Bruell, Chemosphere, 66, 106 (2007).

11. I.H. Cho and K.D. Zoh, Dyes Pigments, 75, 533 (2007).
12. Y. Wu, S. Zhou, F. Qin, X. Ye and K. Zheng, J. Hazard. Mater, 180, 456 (2010)

13. I. Arslan-Alaton, G. Tureli and T. Olmez-Hanci, J. Photochem. Photobiol. A, 202, 142 (2009).

14. S. Garcia-Segura, L.C. Almeida, N. Bocchi and E. Brillas, J. Hazard. Mater., 194, 109 (2011).

15. A.R. Khataee, M. Zarei and S.K. Asl, J. Electroanal. Chem., 648, 143 (2010).

16. I. Yahiaoui, F. Aissani-Benissad, F. Fourcade and A. Amrane, Environ. Prog. Sustain. Energy, 31, 515 (2012).

17. M.J. Lee, Y.S. Kim, C.K. Yoo, J.H. Song and S.J. Hwang, Environ. Technol., 31, 7 (2010).

18. L. Lei, Q. Dai, M. Zhou and X. Zhang, Chemosphere, 68, 1135 (2007).

19. A. Kumar, B. Prasad and I.M. Mishra, J. Hazard. Mater, 150, 174 (2008).

20. K.P. Singh, S. Gupta, A.K. Singh and S. Sinha, J. Hazard. Mater, 186, 1462 (2011).

21. C.J. Liang. C.J. Bruell, M.C. Marley and K.L. Sperry, Soil Sediment Contam., 12, 207 (2003).

22. K.C. Huang, Z. Zhao, G.E. Hoag, A. Dahmani and P.A. Block, Chemosphere, 61, 551 (2005)

23. R.H. Waldemer, P.G. Tratnyek, R.L. Johnson and J.T. Nurmi, Environ. Sci. Technol., 41, 1010 (2007).

24. S.Y. Oh, H.W. Kim, J.M. Park, H.S. Park and C. Yoon, J. Hazard. Mater, 168, 346 (2009).

25. S.X. Li, D. Wei, N.K. Mak, Z.W. Cai, X.R. Xu, H.B. Li and Y. Jiang, J. Hazard. Mater., 164, 26 (2009).

26. P. Nfodzo and H. Choi, Chem. Eng. J., 174, 629 (2011).

27. B. Jancic-Stojanovic, A. Malenovic, D. Ivanovic, T. Rakic and M. Medenica, J. Chromatogr. A, 1216, 1263 (2009).

28. M.A. Bezerra, R.E. Santelli, E.P. Oliveria, L.S. Villar and L.A. Escaleria, Talanta, 76, 965 (2008)

29. R.H. Myers and D.C. Montgomery, Response Surface Methodology: Process and Product Optimization using Designed Experiments, John Wiley \& Sons, USA, edn. 2 (2002).

30. S. Hammami, N. Oturan, N. Bellakhal, M. Dachraoui and M.A. Oturan, J. Electroanal. Chem., 610, 75 (2007).

31. S. Ghasempur, S.F. Torabi, S.O. Ranaei-Siadat, M. Jalali-Heravi, N. Ghaemi and K. Khajeh, Environ. Sci. Technol., 41, 7073 (2007).

32. H.L. Liu and Y.R. Chiou, Chem. Eng. J., 112, 173 (2005).

33. A.R. Khataee, Environ. Technol., 31, 73 (2010).

34. M.J. Anderson and P.J. Whitcomb, RSM Simplified, Optimizing Processes using Response Surface Methods for Design of Experiments, CRC Press Taylor \& Francis Group, New York (2005).

35. W.J. Mcelroy and S.J. Waygood, J. Chem. Soc. Faraday Trans., 86, 2557 (1990).

36. J.D. Laat and T.G. Le, Environ. Sci. Technol., 39, 1811 (2005).

37. M.S. Tsao and W.K. Wilmarth, J. Phys. Chem., 63, 346 (1959).

38. B. Gozmen, M. Turabik and A. Hesenov, J Hazard. Mater., 164, 1487 (2009).

39. E. Brillas, M.A. Banos and J.A. Garrido, Electrochim. Acta, 48, 1697 (2003).

40. Design-Expert Software version 8.00 User's Guide (2010).

41. B. Neppolian, H. Jung, H. Choi, J.H. Lee and J.W. Kang, Water Res., 36, 4699 (2002). 